\title{
The CAMS Approach to Suicide Risk: Philosophy and Clinical Procedures
}

\author{
By David A. Jobes
}

\begin{abstract}
The various and considerable challenges to effectively assessing and treating suicidal patients have truly plagued the field of suicidology for many years (Jobes, Rudd, Overholser, \& Joiner, 2008). The Collaborative Assessment and Management of Suicidality (CAMS) is a relatively new therapeutic clinical framework that endeavors to address a number of these inherent challenges (Jobes, 2006). The CAMS approach described in this article has applied and adapted seminal work of many wellknown clinical suicidologists who pioneered new and innovative ways of thinking about suicidal states with related implications for clinical care therein.
\end{abstract}

For example, key conceptual and theoretical contributors to this particular approach include Shneidman (1985), Beck (Beck et al., 1979), Baumeister (1990), Orbach (2001), Linehan, (1993), Maltsberger (1986), and Rudd (Rudd et al, 2001). Moreover, the CAMS approach to care is heavily informed by empirical evidence-particularly clinical trial research of effective treatments (e.g., Brown et al., 2005; Linehan et al., 2006). This article is meant to provide a broad overview to the evolving CAMS approach, with a particular emphasis on its philosophy and clinical procedures. The article concludes with a brief discussion about the current scientific status of CAMS as on-going randomized clinical trails are being actively pursued.

Simply stated, the CAMS approach to suicidal patients is fundamentally focused on the development of a strong therapeutic relationship with a suicidal person (i.e., the clinical alliance is the essential vehicle for delivering a potentially lifesaving series of clinical interventions). Within CAMS this goal is largely achieved by intentionally engaging the suicidal patient as an active participant in the assessment of their own suicidal risk and by collaborating with the patient as a "co-author" of their suicide-specific treatment plan. Thus, CAMS is both a philosophy of care and a series clinical procedures (guided by the use of the Suicide Status Form-SSF) that are designed to eliminate suicide as means of coping while also helping to increase reasons for living.

\section{Philosophical Aspects of CAMS}

As I have described elsewhere in depth (Jobes, 1995; 2000; 2006) the CAMS approach fundamentally conceptualizes suicide differently from how many mental health professionals were trained to think about working with suicide risk in clinical practice. For example, CAMS philosophy forthrightly asserts that suicidal thinking and behaviors are often a perfectly sensiblealbeit worrisome and often troublingresponse to intense psychological pain and suffering. In a similar sense, I would contend that all suicidal persons have struggles that are rooted in legitimate needs and concerns-c.f., Orbach's (2001) notion of "empathy for suicidal wish." For example, most suicidal people feel they simply cannot bear the pain they are in and they understandably seek an escape from their suffering. Others desperately want their loved ones to know how much they suffer or feel compelled to unburden those who love them. Still other patients, in acute psychiatric distress, may feel compelled to perform acts of self harm as a capitulation to punitive voices they hear within a psychotic state. In each of these scenarios, from the intra-subjective perspective of the suicidal person, there is a perfectly reasonable and understandable explanation for suicidal thoughts and behaviors. In my view clinicians too often view suicidal thoughts and feelings through a moralistic and judgmental lens. In turn, such clinicians often feel compelled to shame the patient for having these feelings (c.f., Linehan, 1993). Within CAMS philosophy we endeavor never to judge or moralize; shaming the patient about suicidal thoughts is anathema to the entire spirit of the approach. In CAMS we simply seek to understand how suicidal thoughts and behaviors "work" for the suicidal patient. When we truly understand the "functional" aspects of suicidality, we are then much better positioned to clinically propose alternative and less life threatening ways of coping and getting one's needs met. When a clinician earnestly embraces this kind of approach and tone, the net result is that the suicidal patient feels understood, respected, and appreciated for these (often scary) ways of thinking and feeling.

Beyond this attitude, the CAMS clinician is also quite transparent about their inherent bias - this is unabashedly a suicide prevention-oriented approach within clinical care. Thus, we would never endorse suicide as a viable or desirable "treatment option." Moreover, we are always forthright about laws related to near term or imminent risk of suicide that may require a voluntary or involuntary hospitalization of the patient. While CAMS emphasizes working on an outpatient basis, the approach is not fundamentally opposed to inpatient care and would never advocate defying relevant legal statutes pertaining to near term risk of self harm.

To make this set of ideas a bit more concrete, imagine the following interaction between a CAMS clinician and a hypothetical suicidal patient. This dialogue embodies key features of the CAMS philosophy of care.

Patient: I suffer so much and no one seems to care; my husband just ignores me - he gets mad at me and tells me to get over it, snap out of it!

Clinician: You feel like no one appreciates your struggles, particularly the person want you most want to care?

Patient: It's not just him, it's everybodymy parents, my kids, and my so called friends...you know I honestly think sometimes they would all be better off without me...

Clinician: It sounds like you feel that you have become a burden to them? Does this view of things ever lead you to thoughts of suicide?

Patient: Well yes, I have actually thought about suicide quite a bit lately. 
Clinician: I see... and when you think about suicide does it upset you or comfort you? Does it frighten you? Or instead, does it give you a feeling of control and power over your suffering?

Patient: It is more the latter because it does make me feel like there is at least one thing I can do about this whole wretched situation that I am in...I just can't bear the pain...it is all too much for me... Clinician: I see...well let's be frank...of course suicide is an option that many people use to cope with these exact feelings. And yet if it was the best thing to do, it seems unlikely that you would be here with me in a mental health care setting, right? From my bias, while I acknowledge the option of suicide for some people, I would like to see if we could find a way to end your pain, and get your needs met, without you needing to take your life. In my mind, you have everything to gain and really nothing to lose by earnestly trying to engage in a life-saving treatment. There is a treatment I would like to try with you called "CAMS"-it is designed to help you learn to cope differently and better and it could help you get your needs met without having to rely on suicide. To this end, I wonder if I could persuade you - if you would consider - engaging for 3 months in this suicide-focused treatment...I really think it could be quite helpful to you. Patient: Well that is asking a lot...I really don't know if I am up for doing something like that...

Clinician: Yes, I understand; but then again you have everything to gain and really nothing to lose. While it is not my preferred means of coping, you always have the prospect of suicide to fall back on later when you are not engaged in a life saving clinical treatment. But for now, I would like to see if we could find a way to make this life more worth living through this approach. Given the life and death consequences, I do not think it is too much to ask of you to give this CAMS approach a go for three months... what do you say?

Patient: I guess we can try, maybe it can help? But you are right, the reason I am here is that I am just not yet ready to exercise my suicide option... How exactly do we do this CAMS?
For many clinicians the above interaction may seem provocative and it may make them uncomfortable. I would contend however that the above interaction is honest, transparent, empathic, and creates the best possible conditions for engaging a suicidal person in a potentially life-saving course of clinical care. Because CAMS so heavily emphasizes informed consent, full and transparent disclosure of clinician biases and agenda, there is a kind of comfort and sense of control within this approach that provides a real prospect for collaboratively learning how the clinical dyad can save the patient's life by developing alternative ways of coping rendering suicidal coping obsolete.

\section{CAMS Clinical Procedures}

While philosophical aspects of CAMS are an important foundation, the approach itself is made up of a series of clinical procedures that have been developed and empirically studied in real-world clinical settings (Jobes, Bryan, \& NealWalden, 2009). As noted at the outset, the CAMS approach employs the use of a multipurpose SSF tool (refer to p. 5 and 6 for an example of the first two pages). The full SSF (seven total pages) provides a means for: (a) the initial assessment and documentation of suicidal risk, (b) the initial development and documentation of a suicide-specific treatment plan, (c) the tracking and documentation of on-going suicidal risk assessment and up-dates of the treatment plan, and (d) the ultimate accounting and documentation of clinical outcomes. The most detailed discussion of CAMS procedures can be found elsewhere (Jobes, 2006). However, Jobes and Drozd (2004) have succinctly described the following step-by-step process for using CAMS in outpatient care.

\section{Step 1 - Early Identification of Risk}

Typically the entry point for a new or ongoing patient to be engaged in CAMS occurs when a patient self-reports current suicidal ideation. While a patient's verbal self-report of ideation is an acceptable entry point to CAMS, the preferred and recommended approach is for CAMS to be triggered by a psychometrically sound symptom-oriented assessment tool which typically have a suicide question embedded among other symptom-related questions (for a full discussion of the SSF "Core Assessment" and psychometrics see Jobes, 2006 and Conrad et al., in press). For our part, we think of the regular use of brief symptom assessments collected at every clinical contact is akin to medical personnel routinely taking a patient's vital signs. Moreover, such tools provide extensive documentation and opportunities to study the nature of treatment process and outcomes. Whatever the case, early identification of suicidality is crucial to using CAMS and fully realizing the benefits of collaborative assessment and treatment planning. Clearly, suicidal ideation is not something that should be identified in the last ten minutes of a clinical hour. In CAMS, current suicidal thoughts are to be identified within the first ten minutes of clinical contact and addressed as forthrightly as possible.

\section{Step 2 - Collaborative Assessment Using the SSF}

CAMS is thus triggered by the presence of current suicidal ideation as revealed through a symptom assessment form or verbal query. The collaborative in-depth assessment of suicidal risk thus begins by asking the patient for permission to literally take a seat next to them in order to complete the first page of the Suicide Status Form together. In this fashion, a clipboard (or laptop) is handed back and forth between the patient and clinician during the assessment; literally and figuratively the dyad endeavor to work off the same (assessment) page. As shown, the first page of the SSF involves completion of various rating scales, qualitative assessments, and rankings. These assessment constructs provide plenty of opportunity for discussion and joint effort. The SSF assessment provides an important framework for understanding the idiosyncratic nature of the patient's suicidality so that both parties can intimately appreciate the patient's suicidal experience. Completion of page 1 (i.e., Section A) of the SSF typically takes $10-15$ minutes. This initial joint assessment activity then leads to the clinician taking back the clipboard (or lap-top) and completing the clinical 


\section{SUICIDE STATUS FORM-III (SSF III) INITIAL SESSION}

Patient: $\quad$ Clinician: $\_$Date: _ Time:
\begin{tabular}{|l} 
Section A (Patient): \\
Rate and fill out each item according to how you feel right now.
\end{tabular}
Rank Then rank items in order of importance 1 to 5 ( $1=$ most important to $5=$ least importance)

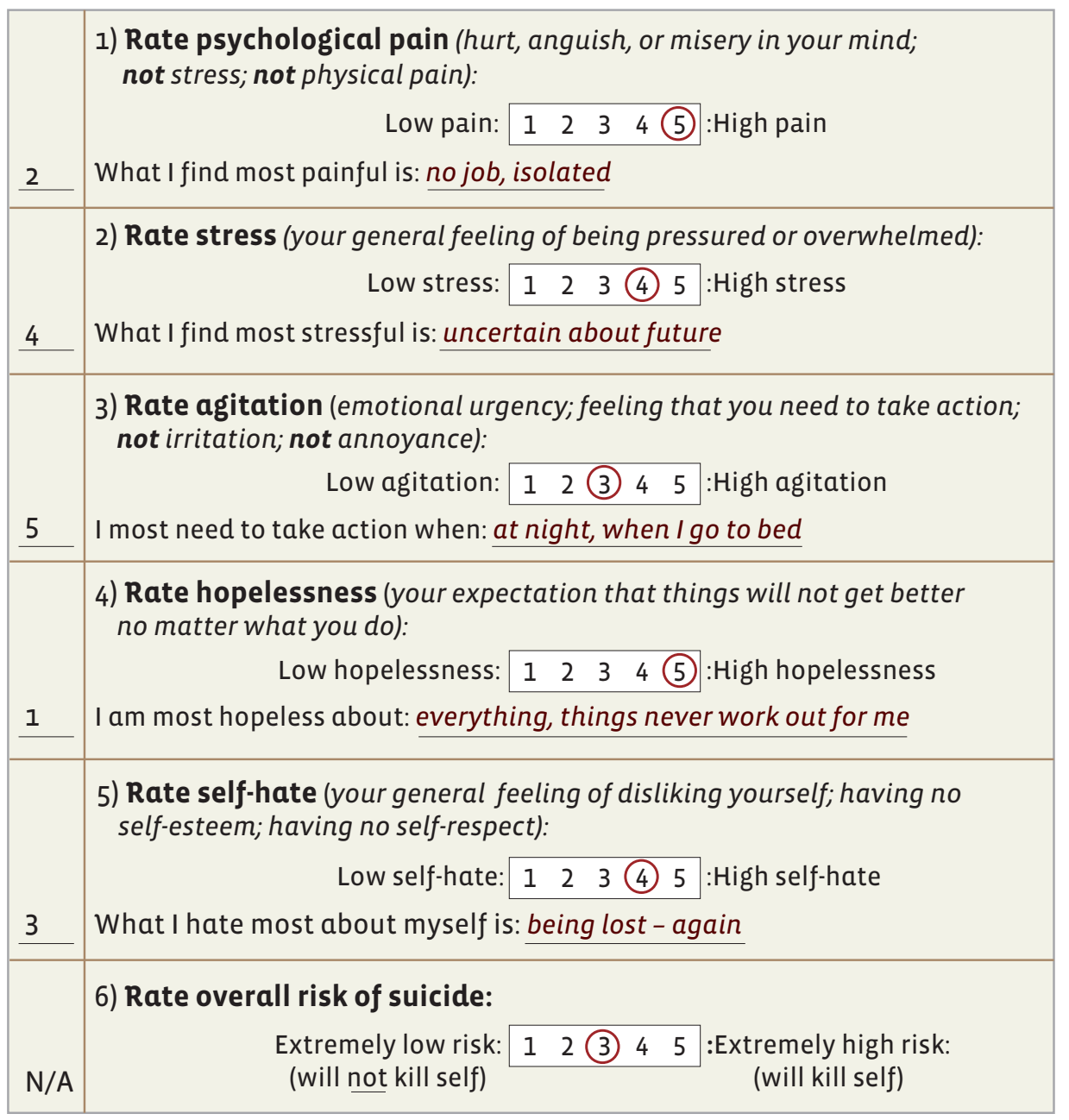

1) How much is being suicidal related to thoughts and feelings about yourself? Not at all: $\begin{array}{lllll}1 & 2 & 3 & 4 & \text { (5) : Completely }\end{array}$

1) How much is being suicidal related to thoughts and feelings about others?

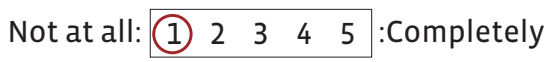

Please list your reasons for wanting to live and your reasons for wanting to die. Then rank in order of importance 1 to 5 .

\begin{tabular}{|l|ll|l|}
\hline Rank & REASONS FOR LIVING & Rank & REASONS FOR DYING \\
\hline 3 & my intelligence & 2 & things never work out \\
\hline 1 & a good job & 1 & can't take the pain \\
\hline 2 & finding someone to love & 3 & won't find healthy relationship \\
\hline 4 & my brother & 4 & I hate myself like this \\
\hline
\end{tabular}

I wish to live to the following extent:

Not at all: $\begin{array}{llllllllll} & 1 & 2 & 3 & 4 & 5 & 6 & 7 & 8 & \text { :Very much }\end{array}$

I wish to die to the following extent:

Not at all: $\begin{array}{llllllllll} & 1 & 2 & 3 & 4 & 5 & 6 & 7 & 8 & \text { :Very much }\end{array}$

The one thing that would help me no longer feel suicidal would be: to find a job and a good relationship
The SSF III is reproduced with the express permission of The Guilford Press

assessment at the top of page 2 (i.e., Section B) which was specifically constructed to assess for the most pernicious risk variables according to recent empirical research (Joiner, Walker, Rudd, \& Jobes, 1999; Oordt et al., 2003).

\section{Step 3 - Collaborative Treatment Planning}

As can be seen in the example, when sections $\mathrm{A}$ and $\mathrm{B}$ are complete, the dyad is then in a position to "co-author" the Outpatient Treatment Plan (Section C). Critically, both parties have achieved together a thorough understanding about the patient's suicidal experience, thereby revealing what must be done to achieve and justify outpatient care. Outpatient care is the explicit goal of the CAMS clinician, which represents perhaps a different orientation from conventional thinking which can be biased in favor of inpatient care (Jobes, 2000). In this regard, the first problem to address is self harm potential and the first goal and objective is outpatient safety. By beginning the focus on outpatient care, the dyad can work to figure out the specific interventions and elements of a "Crisis Response Plan" which must be established for outpatient care to proceed (refer to Rudd et al., 2001). Two other suiciderelevant problems, goals and objectives, should then be identified from sections $A$ and $B$ assessment data obtained from the SSF. Critically, CAMS relies on the Crisis Response Plan as the major intervention for Problem \#1. In our current treatment-oriented research, the Crisis Response Plan must include: (a) elimination of access to lethal means, (b) development and use of a "Crisis Card," (c) efforts to interpersonally connect the patient to others (refer to Jobes, 2006). When the Outpatient Treatment Plan is complete, the patient is then operationally understood to be on Suicide Status; on-going suicide risk is then monitored and tracked at each subsequent clinical contact (using the SSF Suicide Tracking Form). As discussed by Jobes (2006) an additional page of documentation is also included with the SSF that provides an opportunity to document mental status, 
SUICIDE STATUS FORM-III (INITIAL SESSION) (PAGE 2)

\section{Section B (Clinician):}

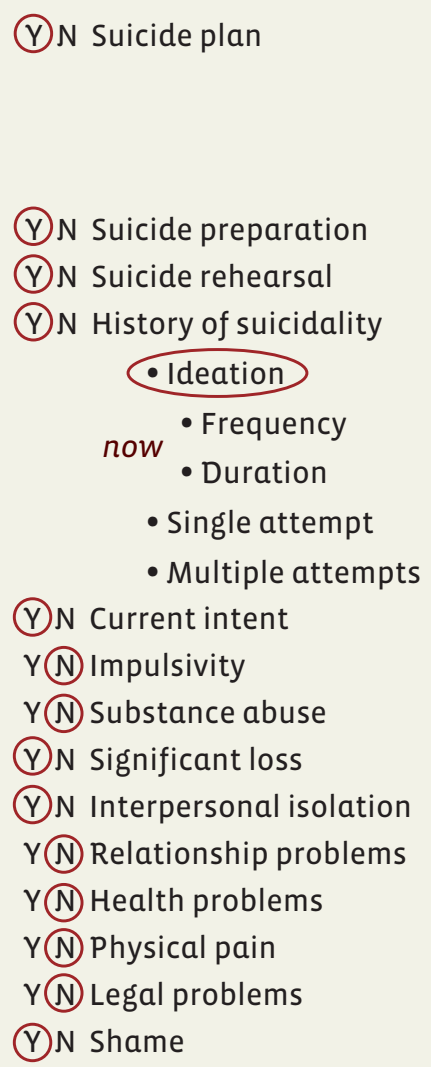

\begin{tabular}{|c|c|c|}
\hline When: & not sure & \\
\hline Where: & jump off bridge & \\
\hline How: & jump & (Y) $N$ Access to means \\
\hline How: & maybe use rifle & $\mathrm{Y}(\mathrm{N})$ Access to means \\
\hline Describe: & wrote note to brother & (not now) \\
\hline
\end{tabular}

Describe: as a teen had significant suicidal thoughts

1-2 per day _ per week seconds 30 minutes 1

Describe: $n / a$

Describe: $\mathrm{n} / \mathrm{a}$ no attempts, only ideation

Describe: feel must do something for pain

Describe:

Describe:

Describe: obsessing over past girfriend

Describe: feels he has cut himself off from others

Describe:

Describe:

Describe:

Describe:

Describe:

over father \& family issues
Section B (Clinician): OUTPATIENT TREATMENT PLAN (Refer to Sections A \& B)

\begin{tabular}{|c|c|c|c|c|}
\hline $\begin{array}{c}\text { Problem } \\
\#\end{array}$ & $\begin{array}{c}\text { Problem } \\
\text { description }\end{array}$ & $\begin{array}{c}\text { Goals and objectives } \\
\text { Evidence for attainment }\end{array}$ & $\begin{array}{c}\text { Intervention } \\
\text { (Type and frequency) }\end{array}$ & $\begin{array}{c}\text { Estimated \# } \\
\text { sessions }\end{array}$ \\
\hline 1 & $\begin{array}{c}\text { Self-harm } \\
\text { potential }\end{array}$ & $\begin{array}{c}\text { Outpatient } \\
\text { safety }\end{array}$ & $\begin{array}{c}\text { Crisis response plan } \\
\text { Crisis card/avoid bridge/ } \\
\text { read Choosing to live }\end{array}$ & $\begin{array}{l}2 \times / \text { wh } \\
\text { for } 4 \text { weeks }\end{array}$ \\
\hline 2 & $\begin{array}{c}\text { unemploy- } \\
\text { ment }\end{array}$ & find a job & $\begin{array}{c}\text { vocational assessment } \\
\text { \& counseling }\end{array}$ & 4 weeks \\
\hline 3 & $\begin{array}{c}\text { social } \\
\text { isolation }\end{array}$ & $\uparrow$ social support & $\begin{array}{c}\text { Problem solve to } \\
\text { social support }\end{array}$ & 4 weeks \\
\hline
\end{tabular}

YES $V$ NO Patient understands and commits to outpatient treatment plan?
YES N NO Clear and imminent danger of suicide?

Patient signature

Date

Clinician signature

Date diagnosis, overall assessment of risk and case notes (all seven pages of the SSF are available in the Jobes, 2006 text).

Step 4 - Clinical Tracking of Suicide Status

At each subsequent clinical contact, the patient's self report SSF assessment is quickly completed at the start of each session; at the end of the session the Outpatient Treatment Plan is revisited, revised, and/or up-dated (side-by-side) depending on clinical progress or any new emerging suicidal issues that need to become a focus of treatment.

\section{Step 5 - Clinical Resolution of Suicide} Status

Three consecutive sessions of no suicidal thoughts, feelings, and behaviors marks the resolution on suicide risk; the SSF Suicide Tracking Outcome Forms are completed and the patient is taken off Suicide Status as CAMS comes to a close (refer to Jobes, 2006; Jobes et al., 1997).

In summary, CAMS engages the suicidal patient differently than conventional approaches, thereby creating a different treatment trajectory. This trajectory is fundamentally shaped by an enhanced therapeutic alliance forged in the shared pursuit of trying to assess and understand what it means for the patient to be suicidal and with that shared knowledge determining how that risk will be clinically managed and eliminated.

\section{Current CAMS Treatment Research}

CAMS is very much a living-breathing and evolving clinical approach that is based on "real world" clinical research (Drozd, Jobes, \& Luoma, 2000; Eddins \& Jobes, 1994; Jobes \& Berman, 1993; Jobes, 1995; 2000; 2003; 2006; Jobes \& Drozd, 2004; Jobes \& Mann, 1999; 2000; Jobes et al., 1997; 2004; 2005; 2007; in press). A recent study has replicated and extended earlier research (Jobes et al., 1997) pertaining to the validity and reliability of the SSF "Core Assessment" (Conrad et al., in press). Moreover, there is a growing body of correlational data providing encouraging results about the clinical use of CAMS and the SSF. 
In one non-randomized control group design, CAMS care was associated with more rapid reductions of suicidal ideation and decreased use of non-mental health care (primary care and emergency department visits) than treatment as usual (Jobes et al., 2005). Moreover, in a recent within-group treatment study of suicidal college students using linear analyses of care over multiple time points, SSF/ CAMS care was associated with marked reductions in overall symptom distress and frequency of suicidal thoughts (Jobes et al., in press). Based on these encouraging correlational data, we are currently pursuing three randomized clinical trial feasibility studies of CAMS in two outpatient clinics and in one inpatient setting. With accumulating feasibility data we will soon be in position to pursue well-powered "gold standard" randomized clinical trials to rigorously study the potential effectiveness of the CAMS approach.

\section{Summary}

CAMS is an evolving therapeutic framework supported by 15 years of clinical research. As described in this article, the approach emphasizes both a therapeutic philosophy and a set of clinical procedures. CAMS utilizes the SSF as a multipurpose road map that guides clinical assessment, treatment, and tracking of suicidal risk. The approach is designed to foster a strong therapeutic alliance and increase motivation within the suicidal patient. Indeed, suicidal patients themselves are the key to successful CAMS care, as they acquire and craft new coping skills and perhaps begin a process of finding purpose and meaning in a life that may have otherwise been lost to suicide.

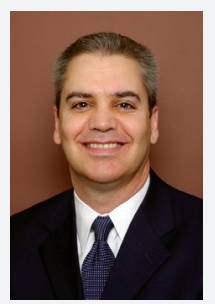

David A. Jobes, Ph.D. is a professor of psychology and co-director of clinical training in the Ph.D. clinical psychology training program at The Catholic University of America in Washington DC. Dr. Jobes has published extensively on suicide prevention in scientific journals and various books on the topic. He consults widely and routinely provides professional training in clinical suicidology, ethics, and risk management.

\section{References}

Baumeister, R. F. (1990). Suicide as escape from self. Psychological Review, 97, 90-113.

Beck, A. T., Rush, A. J., Shaw, B. F., \& Emery, G. (1979). Cognitive therapy of depression. New York: Guilford Press.

Brown, G. K., Ten Have, T., Henriques, G. R., Xie, Sharon X., Hollander, J. E., \& Beck, A. T. (2005). Cognitive therapy for the prevention of suicide attempts: A randomized controlled trial. Cognitive Therapy for the Prevention of Suicide. Journal of the American Medical Association, 29, $563-570$

Conrad, A. K., Jacoby, A. M., Jobes, D. A., Lineberry, Shea, C., Fritsche, K., Schmid, P., Ellenbecker, S., Grenell, J., \& Arnold-Ewing, T. (in press). A psychometric investigation of the suicide status form with suicidal inpatients. Suicide and Life-Threatening Behavior.

Drozd, J. F., Jobes, D. A., \& Luoma, J. B. (2000). The collaborative assessment and management of suicidality in air force mental health clinics. The Air Force Psychologist, 18, 6-11.

Eddins, C. L., \& Jobes, D. A. (1994). Do you see what I see? Patient and clinician perceptions of underlying dimensions of suicidality. Suicide and Life-Threatening Behavior, 24, 170-173.

Jobes, D. A. (1995). The challenge and the promise of clinical suicidology. Suicide and Life-Threatening Behavior, 25, 437-449.

Jobes, D. A. (2000). Collaborating to prevent suicide: A clinical-research perspective. Suicide and Life-Threatening Behavior, 30, 8-17.

Jobes, D. A. (2003). Understanding suicide in the 21 st century. Preventing Suicide: The National Journal, 2, 2-4.

Jobes, D. A. (2006). Managing suicidal risk: A collaborative approach. New York: The Guilford Press.

Jobes, D. A., \& Berman, A. L. (1993). Suicide and malpractice liability: Assessing and revising policies, procedures, and practice in outpatient settings. Professional Psychology: Research and Practice, 24, 91-99.

Jobes, D. A., Bryan, C. J., \& Neal-Walden, T. A. (2009). Conducting suicide research in naturalistic clinical settings. Journal of Clinical Psychology, 65, 1-14

Jobes, D. A., \& Drozd, J. F. (2004). The CAMS approach to working with suicidal patients. Journal of Contemporary Psychotherapy, 34, 73-85.

Jobes, D. A., Jacoby, A. M., Cimbolic, P., \& Hustead, L. A. T. (1997). The assessment and treatment of suicidal clients in a university counseling center. Journal of Counseling Psychology, 44, 368-377.

Jobes, D. A., Kahn-Greene, E., Greene, J., \& Goeke-Morey, M. (in press). Clinical improvements of suicidal outpatients: Examining suicide status form responses as moderators. Archives of Suicide Research.
Jobes, D. A., \& Mann, R. E. (1999). Reasons for living versus reasons for dying: Examining the internal debate of suicide. Suicide and LifeThreatening Behavior, 29, 97-104.

Jobes, D. A., \& Mann, R. E. (2000). Letters to the editor-Reply. Suicide and Life-Threatening Behavior, 30, 182.

Jobes, D. A., Nelson, K. N., Peterson, E. M., Pentiuc, D., Downing, V., Francini, K., \& Kiernan, A. (2004). Describing suicidality: An investigation of qualitative SSF responses. Suicide and Life-Threatening Behavior, 34, 99-112.

Jobes, D. A, Moore, M., \& O'Connor S. S. (2007).

Working with suicidal clients using the collaborative assessment and management of suicidality (CAMS). Journal of Mental Health Counseling, 29, 283-300.

Jobes, D. A., Wong, S. A., Conrad, A., Drozd, J. F., \& Neal-Walden, T. (2005). The Collaborative assessment and management of suicidality vs. treatment as usual: A retrospective study with suicidal outpatients. Suicide and Life-Threatening Behavior, 35, 483-497.

Jobes, D. A., Rudd, M. D., Overholser, J. C., \& Joiner, T. E. (2008). Ethical and competent care of suicidal patients: Contemporary challenges, new developments, and considerations for clinical practice. Professional Psychology: Research and Practice, 39, 405-413.

Joiner, T. E., Walker, R. L., Rudd, M. D., \& Jobes, D. A. (1999). Scientizing and routinizing the assessment of suicidality in outpatient practice. Professional Psychology: Research and Practice, 30, 447-453.

Linehan, M. M. (1993a). Cognitive behavioral therapy of borderline personality disorder. New York: Guilford Press.

Linehan, M. M., Comtois, K. A., Murray A. M. Brown, M. Z., Gallop, R. J., Heard, H. L., Korslund, K. E., Tutek, D. A., Reynolds, S. K., \& Lindenboim, N. (2006). Two-year randomized controlled trial and follow-up of dialectical behavior therapy vs. therapy by experts for suicidal behaviors and borderline personality disorder. Archives of General Psychiatry, 63, 757-766.

Maltsberger, J. T. (1986). Suicide risk: The formulation of clinical judgment. New York: New York University Press.

Oordt, M., Jobes, D., Rudd, M., Fonseca, V., Russ, C., Stea, J., Campise, R., \& Talcott, W. (2005). Development of a clinical guide to enhance care for suicidal patients. Professional Psychology: Research and Practice. 36, 208-218.

Orbach, I. (2001). Therapeutic empathy with the suicidal wish. American Journal of Psychotherapy, $55,166-184$.

Rudd, M. D., Joiner, T., \& Rajab, M. H. (2001). Treating suicidal behavior: An effective, timelimited approach. New York: Guilford.

Shneidman, E. S. (1993). Suicide as psychache: A clinical approach to self-destructive behavior. Northvale, NJ: Aronson. 